\title{
The Saw Gin Stand with Adjustable Movement of the Roll Box
}

\author{
Umarov Akmal, Akhmedkhodzhaev Khamit, Sarimsakov Akramjon, Kenjaeva Muazzam \\ Namangan Institute of Engineering and Technology, Namangan, Uzbekistan \\ Email: akmal.umarov@mail.ru, s.akram_82@mail.ru
}

How to cite this paper: Akmal, U., Khamit, A., Akramjon, S. and Muazzam, K. (2018) The Saw Gin Stand with Adjustable Movement of the Roll Box. Engineering, 10, 486-494.

https://doi.org/10.4236/eng.2018.108034

Received: June 11, 2018

Accepted: August 3, 2018

Published: August 6, 2018

Copyright $\odot 2018$ by authors and Scientific Research Publishing Inc. This work is licensed under the Creative Commons Attribution International License (CC BY 4.0).

http://creativecommons.org/licenses/by/4.0/

\begin{abstract}
The article contains information about saw gin used at cotton processing plants. The influence of the density of the seed roll, which is formed in the roll box of the saw gin, on the load of the saw cylinder drive and on the technological characteristics of the machine is considered. As a result of the research, in order to preserve the quality characteristics of fiber and seeds, the author proposes a gin stand with a system for regulating the position of the roll box.
\end{abstract}

\section{Keywords}

Seed Cotton, Ginning of Cotton, Saw Gin Stand, Roll Box, Seed Roll, Load Current, Sensor, Controller

\section{Introduction}

Cotton fiber is the main raw material in the textile industry. Separation of fiber from the seed is called ginning, and the machine that performs this process is gin stand.

The gin stand is the heart of the ginning system. The capacity of the system and the quality and potential spinning performance of the lint depends on the operating condition and adjustment of the gin stand [1] [2] [3].

Let us consider the process of ginning using the example of machines of the “ДП” (DP) series produced in Uzbekistan (Figure 1) [4]. The saw gin consists of a feeder 1 , a roll box 2 , a seed finger 3 , a saw cylinder 4 , a rib grating 5 and a fiber removal mechanism. Ginning occurs as follows. Feeder evenly feeds seed cotton into the roll box. The saw cylinder rotates and hooks the seed cotton fiber with the teeth. The mass of seed cotton rotates inside the roll box and forms a seed-roll. Teeth of saw, having caught the fibers, pass between the ribs (rib slots) 


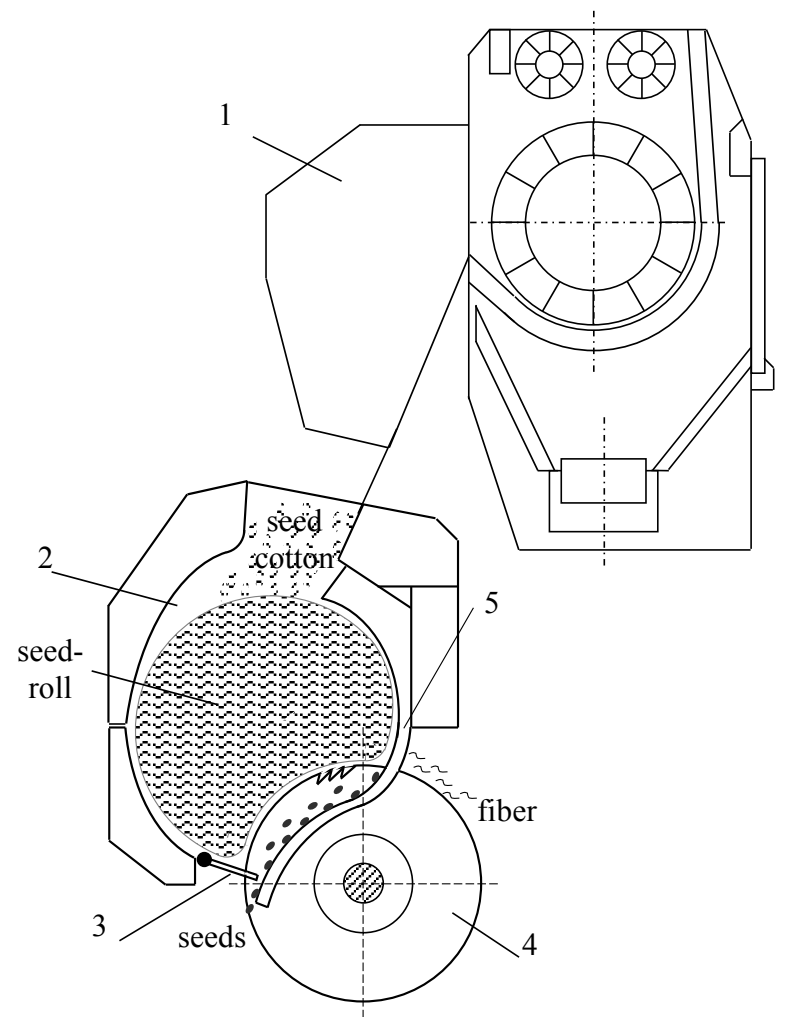

Figure 1. Scheme of “ДП” series saw gin stand. 1: Feeder; 2: Roll box; 3: Seed finger; 4: Saw cylinder; 5: Rib grate.

of the rib grate. The distance between the ribs is $3.2 \mathrm{~mm}$, and the thickness of the saw blade is $0.95 \mathrm{~mm}$. The fiber passes between the ribs, and the seeds do not pass, since the size of the seeds is greater than the distance between the ribs. Here there is a process of separating the fiber from the seed, i.e. ginning.

The density of the seed-roll affects the productivity of the machine, the quality of fiber and seeds, the durability of the main working organs, energy consumption and other. With the growth of the density of the seed-roll from the optimal value, fiber and seeds are damaged, the consumption of the motor ( $75 \mathrm{~kW})$ of the saw cylinder increases, leads to "overload" and even engine burnout, and when the density of the seed-roll decreases, the natural qualities of fiber and seeds are also lost, and productivity is reduced. In addition, as the density of the seed-roll increases, the operator manually loosens the seed cotton inside the roll box, which leads to damage and even amputation of the hand. Therefore, the regulation of the density of the seed-roll is one of the main issues of improving the saw gins.

At present, the density of the seed-roll is regulated by changing the feeder speed. But this does not completely solve this problem.

Previously, a solution was proposed to regulate the density of a seed roll. It is established that there is a direct proportional relationship between the total consumed power of the electric motor of the saw gin cylinder and the density of the seed roll. The power $P$ consumed by the electric motor is defined as 
$P=U J \cos \phi$, where $U$ and $J$-is the voltage and current strength, $\phi$ - the angle of phase displacement between them. Since in the electrical network the voltage applied to the gin electric motor is kept constant, this means the existence of such a directly proportional relationship between the strength of the electric current and the density of the seed roll [5] [6] [7].

The saw shaft of the saw cylinder is connected to the shaft of the gin electric motor, which is equipped with a load current monitoring sensor. The electric motor of the feeder is connected with the device for automatic regulation of the feeder operation, consisting of a frequency converter of the supply voltage of the feeder's motor.

Supplying the roll box with a load current change monitoring device, it is possible to control the density of the seed roll and to regulate the volume of material supplied to the roll box.

The invention is explained in the drawing, in which Figure 2 schematically shows a roll box of saw gin. It contains the front apron 1, the frontal block 2 , the rib 3 fixed to it, the saw cylinder 4 , the seed finger 5 and the lower apron 6 . The saw shaft of the saw cylinder 4 is connected to the shaft of the electric motor 9 which is provided with a load current monitoring sensor 10 controlling the device for the automated regulation of the operation of the electric motor of the feeder 11 .

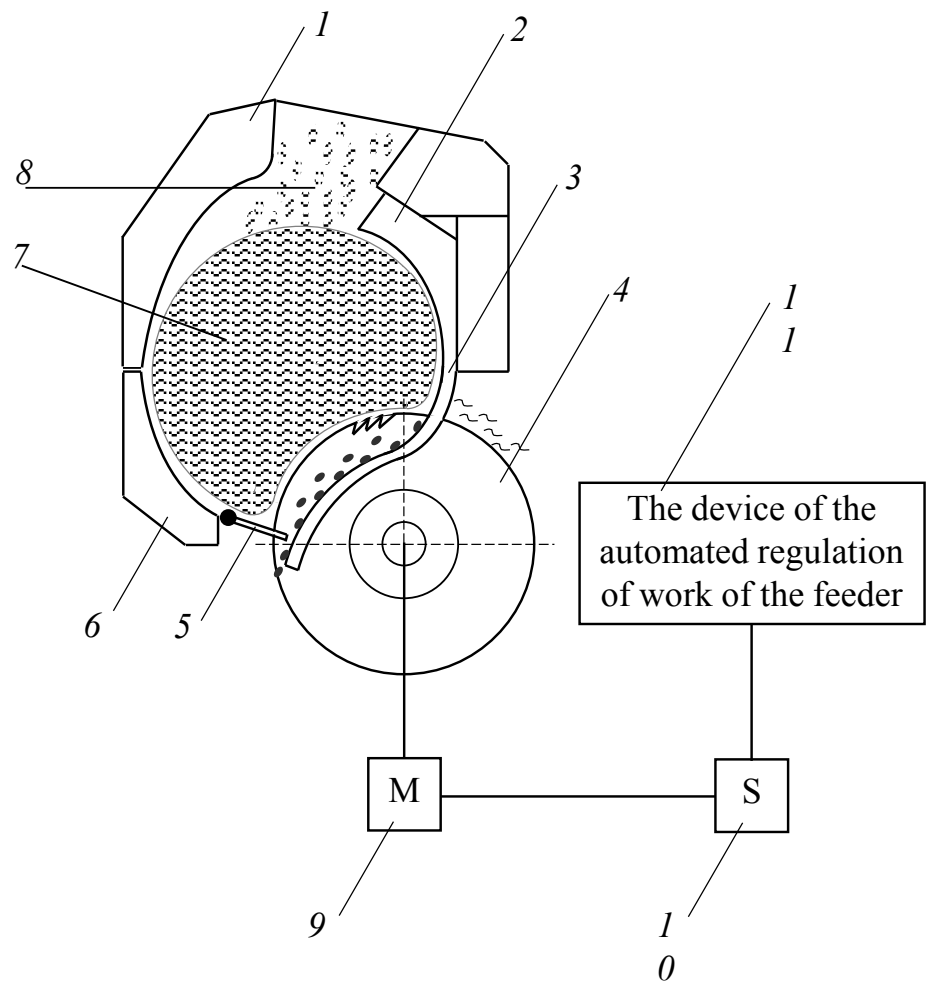

Figure 2. Scheme of saw gin's roll box. 1: Front apron; 2: Frontal block; 3: Rib; 4: Saw cylinder; 5: Seed finger; 6: Lower apron; 7: Seed roll; 8: Seed cotton; 9: Electric motor; 10: Current load monitoring sensor; 11: Device of the automated regulation of work of the feeder. 
The roll box of saw gin works as follows. The incoming seed cotton 8 forms a seed roll 7 which contacts the saw cylinder 4 . From the seed roll 7 through the rib 3 by the saw cylinder 4 , the fiber is removed from the roll box, and the seed output is regulated by the position of the seed finger 5 . When the density of the seed roll 7 changes and the corresponding change in the load current is changed on the electric motor 9 of the saw cylinder 4, the current load monitoring sensor 10 responds to this, controlling the device for automatically adjusting the operation of the feeder's motor 11, which by adjusting the frequency of the supply voltage of the feeder's motor changes its speed and the amount of feed Into the roll box of seed cotton 8 in such a way that the set value of the density of the seed roll is restored.

The following is also proposed, the frequency inverter receives a signal from the load current sensor of the gin's electric motor, which reacts to the change in the density of the seed roll, and regulates the speed of rotation of the feeder's motor, changing the speed of rotation of the feed rollers.

Supplying the feeder with a regulating device due to a change in the speed of the feed rollers makes it possible to control the density of the seed roll and to regulate the volume of the feed material.

The invention is explained by a drawing, in which Figure 3 schematically depicts a gin feeder "ПД" (PD) [8] [9]. It contains feed rolls 1 , a clean cylinder 2, a grid 3, a conveyor for removing impurities 4 , a tray for feeding seed cotton into the roll box of gin 5, an electric motor 6 whose rotational speed is controlled by a

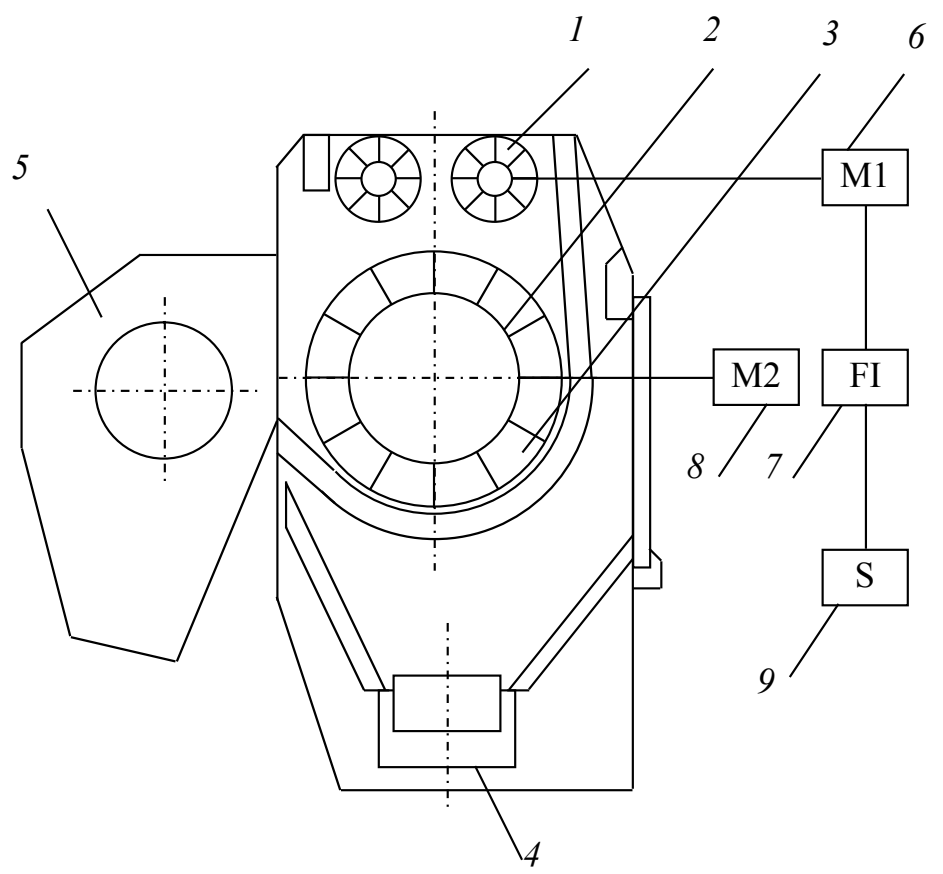

Figure 3. Scheme of saw gin's feeder “ПД” (РD). 1: Feed roll; 2: Clean cylinder; 3: Grid; 4: Conveyor for removing impurities; 5: Tray for feeding seed cotton into the roll box of gin; 6: Electric motor of the feed rollers; 7: Frequency inverter; 8: Electric motor of cleaning cylinder; 9: Sensor of the load current of the gin's electric motor. 
frequency inverter 7 depending on the signal received from the sensor 9 of the load Current of the gin's electric motor on the density of the seed roll located at the place where the power supply of the electric motor of the gin cylinder is fed. To maintain the speed of rotation of the cleaning cylinder constant, regardless of the speed of the feed rollers, it is equipped with a separate electric motor 8 .

The feeder of the saw gin works as follows. When the density of the seed roll is changed by a value higher than the permissible value, the gin's load current sensor gives a signal to the frequency inverter 7 which regulates the speed of the motor 6 rotating the feed rollers 1, thereby changing the feed rate of the seed cotton into the roll box of the gin in such a way that it is restored Set value of the density of the seed roll. The process is stepless and continues in this mode continuously.

However, the delay of the reaction is possible, since the way of seed cotton from feed rollers of feeder to the gin's roll box takes some time.

\section{The Proposed Saw Gin with Adjustable Movement of the Roll Box}

In this connection, in Centro Interdipartimentale di Ricerca "E. Piaggio", Universita di Pisa, Italy, a breadboard gin model was created. It was designed on the Creo-2 program, printed on a 3D printer and assembled with screws (Figure 4).

As the motors M1 and M2 were used Maxon Motor DSX 22S. Sensors S1 and S2 were used Encoder Sensor. The process was controlled by a controller consisting of two electronic boards. All electrical parts were connected with the ERM cable (Figure 4).

The main idea of the development is as follows (Figure 5). As the density of the seed-roll increases, the load current to the motor M1 of the saw cylinder increases and the controller receives a signal. In this case, the moving motor M2 of the roll box moves the roll box from the working area until the load on the saw cylinder is lowered to the optimum value.

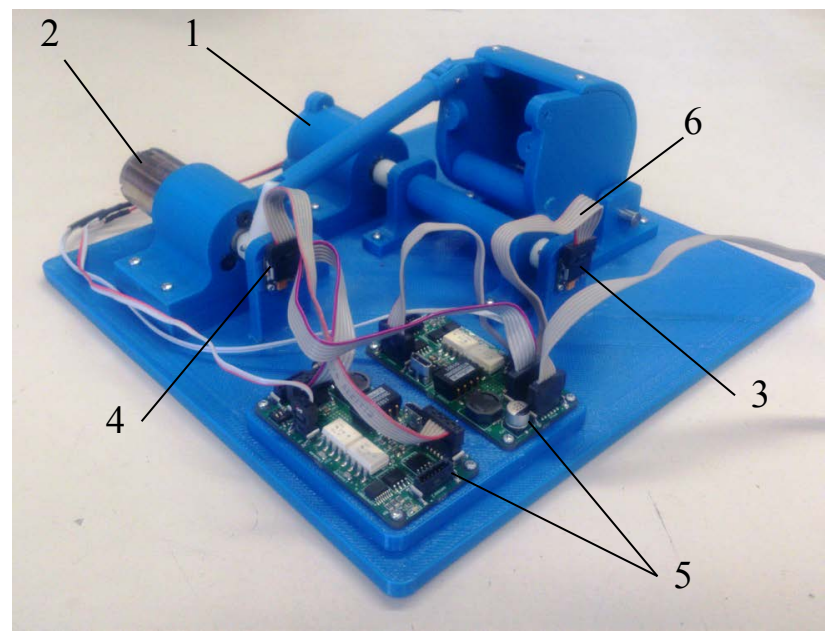

Figure 4. Model of the saw gin with the movement of the roll box. 1: Motor M1; 2: Motor M2; 3: Sensor S1 of motor M1; 4: Sensor S2 of motor M2; 5: Electronic boards; 6: Cable. 


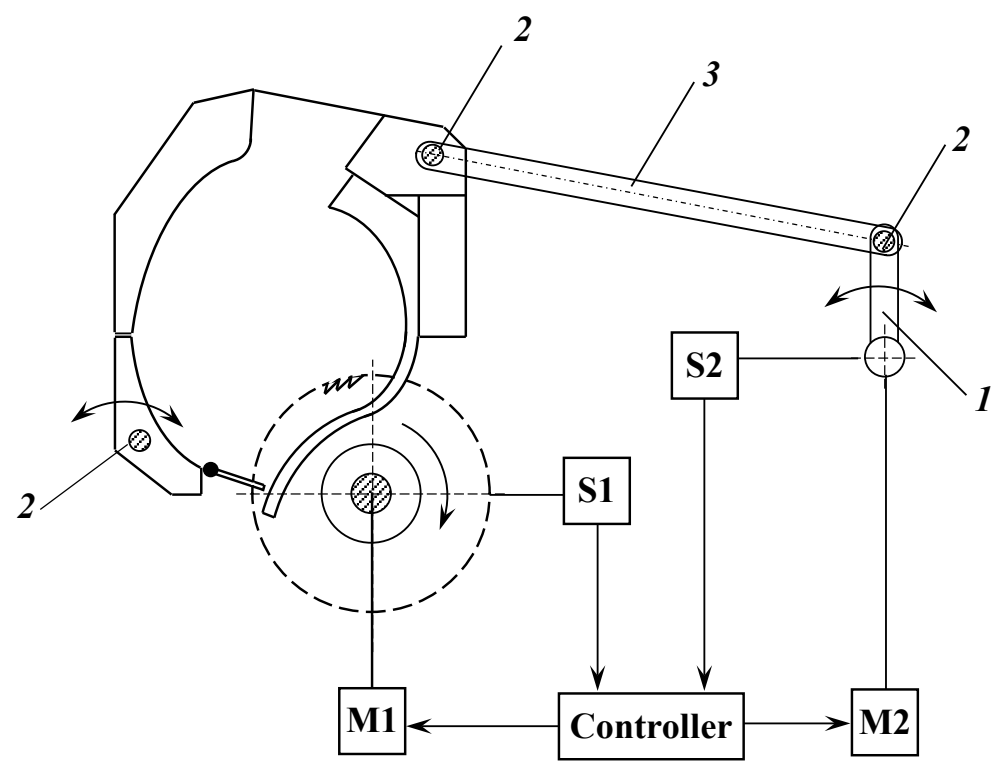

(a)

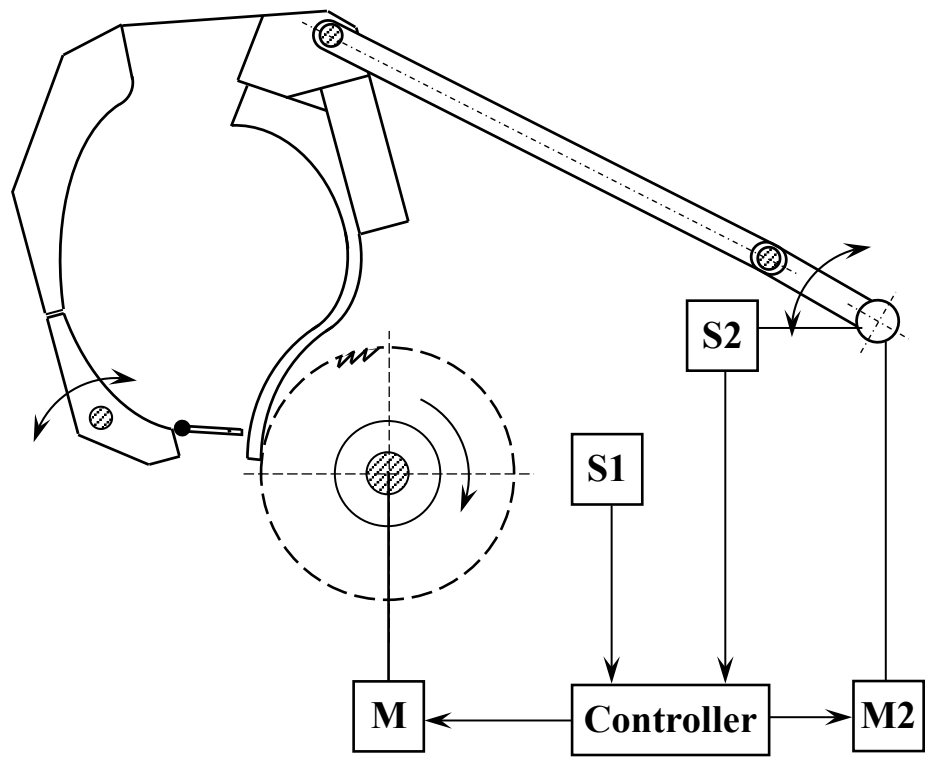

(b)

Figure 5. The scheme of the saw gin with the movement of the roll box. 1: Crankshaft; 2 : Pin; 3: Connecting-rod.

\section{Results}

A control model was developed on the Matlab Simulink program (Figure 6) and graphs were obtained (Figure 7) [10].

In the model Matlab Function Motor 1 was introduced to adjust the M1 motor of the saw cylinder and Matlab Function Motor2 to adjust the motor M2 of the moving roll box, and also Matlab Function1 to adjust the work of both motors. $\mathrm{Qb}$ Move was used from the Qb Move Library to manage the system.

The visibility of the graph shows that as the load current of the motor M1 increases, the motor M2 automatically moves the roll box. 


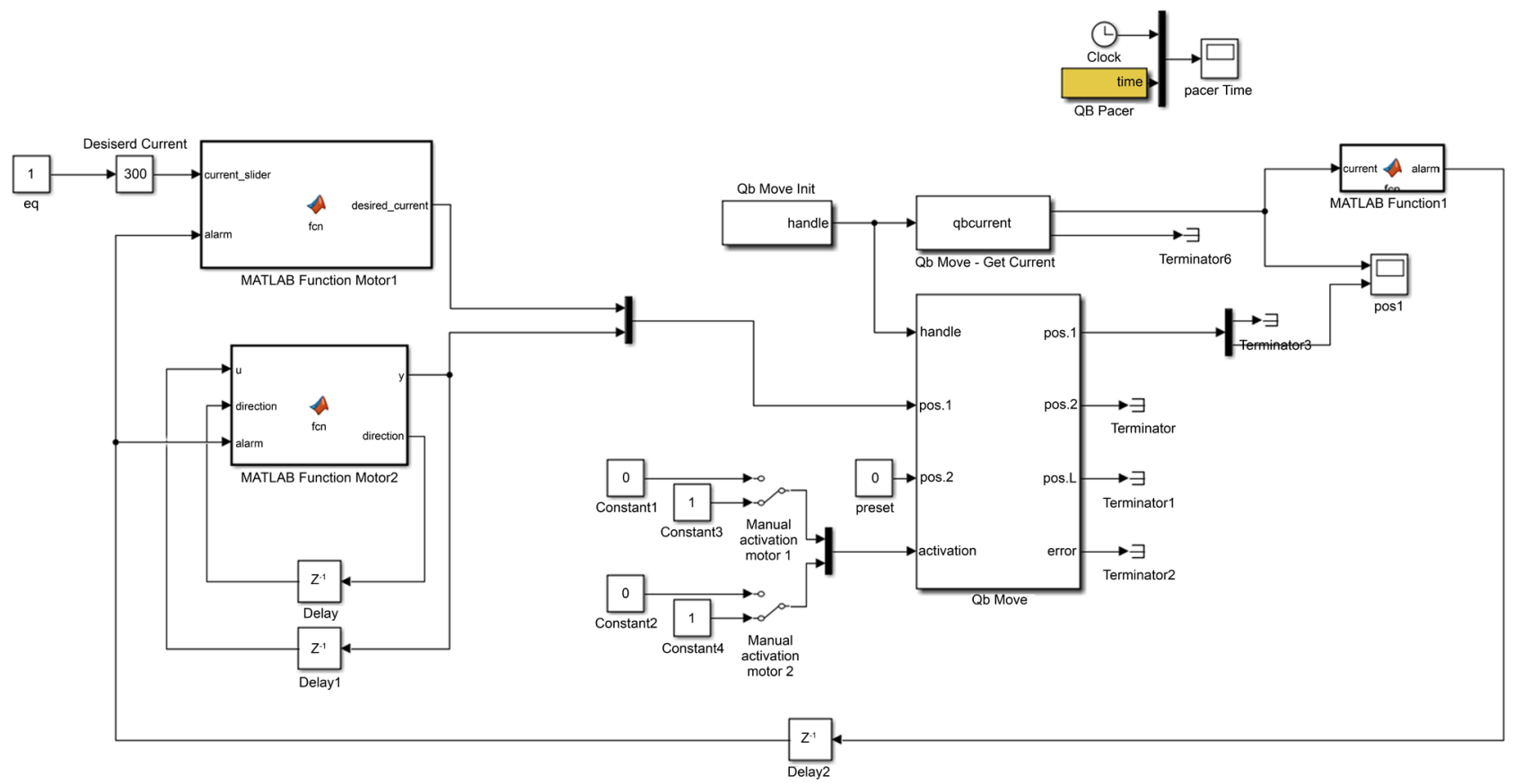

Figure 6. A control model on the Matlab/Simulink program.

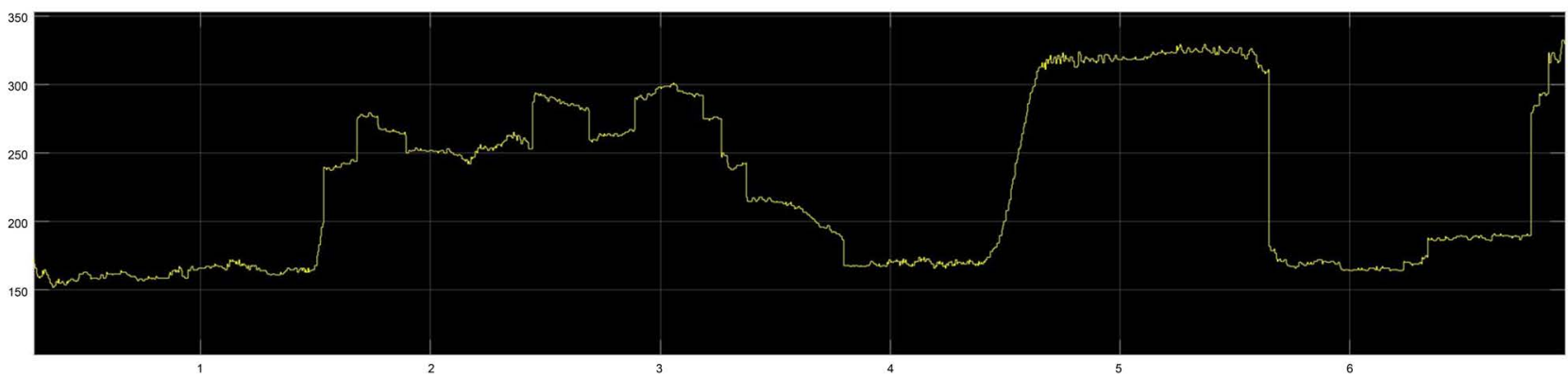

(a)

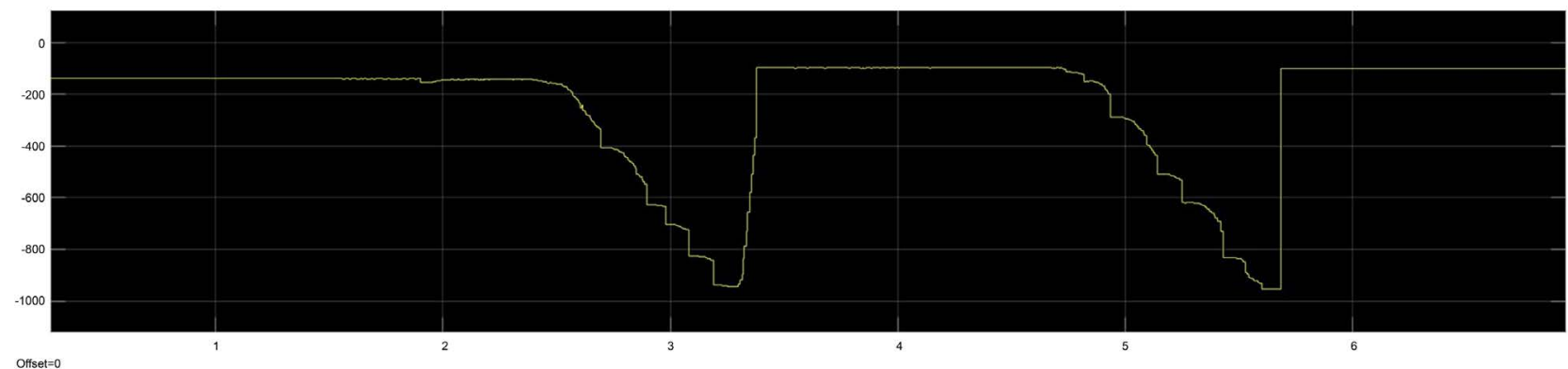

(b)

Figure 7. Graphs of model. (a) Load current of the motor M1 of the cylinder; (b) Moving to the positions of the roll box by the motor M2.

The model works as follows. When the model starts, the M1 motor rotates the saw cylinder. A sponge, pressed onto the cylinder, was used to stimulate the load process of the cylinder. When pressed with a sponge on the cylinder, the load current of the motor M1 increases. When this figure reaches the level of over 250 
$\mathrm{mA}$, the M2 motor starts to move the roll box, stimulating the output of the roll box from the working area. When the sponge is removed, the load current of M1 motor of the saw cylinder decreases, the motor M2 moves the roll box back to the working position. And when the cylinder is pressed hard with a sponge, the load current increases in level to more than $450 \mathrm{~mA}$, the roll box moves as much as possible from the working position and the motor M1 of the cylinder stops.

The experiments showed the operability of the control system by means of moving the roll box and the possibility of using this system in manufacturing.

The use of this system in manufacturing will reduce the amount of time required to operate the machine when it pauses or needs mending, increase productivity of the machine, save the natural qualities of fiber and seeds, increase the amount of working time of saws and ribs, protect the saw cylinder from burning out, and will also protect the worker from damaging his hands while operating the machine.

\section{Conclusions}

1) The process of ginning on DP gin stands was considered.

2) A device is proposed for controlling the density of seed roll by changing the speed of the feed roller motor by a frequency inverter.

3) The model of the device for regulating the position of the roll box depending on the current load of the motor of the saw cylinder is created.

4) Experiments have been carried out to determine the dependence of the load current of the motor of the saw cylinder and the displacement of the roll box.

\section{Conflicts of Interest}

The authors declare no conflicts of interest regarding the publication of this paper.

\section{References}

[1] Anthony, W.S. and Mayfield, W.D. (Eds.) (1994) Cotton Ginners Handbook. Agricultural Handbook 503, U.S. Department of Agriculture, Washington DC, 90.

[2] International Cotton Advisory Committee (2001) Impact of Ginning on Fiber Quality: The Best Ginning Practices. Report of an Expert Panel on Ginning Methods. International Cotton Advisory Committee, Washington DC.

[3] Hughs, E., Holt, G. and Rutherford, R. (2017) Saw Gin Stands. Engineering and Ginning. The Journal of Cotton Science, 21, 60-69.

[4] Burnashev, R.Z., Muradov, R. and Sarimsakov, O.Sh. (2001) Dynamic Task of Interaction of Raw Cotton with Working Bodies of Processing Machines. Journal of Problems of Mechanics, No. 3-4, 55.

[5] Ahmedkhodzhaev, Kh.T., Abduvakhidov, M., Umarov, A.A. and Kshivitsky, O.O. (2011) Roll Box of Saw Gin Stand. Patent of the Republic of Uzbekistan No. FAP 00599, B.I., No. 2, 67.

[6] Akhmedkhodzhaev, Kh.T., Abduvakhidov, M. and Umarov, A. (2012) Development of a System for Regulating the Supply of Gin and Testing in Production Conditions. 
Textile Problems. Journal of Technical Sciences, No. 1, 4-8.

[7] Umarov, A.A. (2008) Investigation of the Regulation of the Density of Seed Roll in the Saw Gin Stand. Journal of Natural and Technical Sciences, No. 2, 333-334.

[8] Ahmedkhodzhaev, Kh.T., Abduvakhidov, M., Umarov ,A.A. and Kshivitsky, O.O. (2011) Feeder of Saw Gin Stand. Patent of the Republic of Uzbekistan No. FAP 00600, B.I., No. 2, 68.

[9] Abduvakhidov, M.A. and Umarov, A.A. (2008) Investigation of Speed Regulation of Electric Drives of Gin Feeders. Journal of Natural and Technical Sciences, No. 2, 328-329.

[10] Sarimsakov, O.Sh. (2016) The Change in Air Pressure Along the Length of the Pipeline Installation for Pneumatic Conveying of Raw Cotton. Journal of Engineering \& Technology, 3, 89-92. http://www.aascit.org/journal/et 